\title{
CICECO: 20 Anos, 20 Seminários
}

O Laboratório Associado CICECO - Instituto de Materiais de Aveiro celebra este ano o seu 20. aniversário. Para celebrar este momento, as comemorações incluem um ciclo de webinars internacionais sobre materiais (IWMat).

O IWMat promoverá uma série de conferências realizadas online para explorar as fronteiras do conhecimento dos temas relevantes na área de ciência e tecnologia de materiais, cruzando as áreas de energia, tecnologia da informação e comunicação, sustentabilidade e saúde, com foco na investiģação desenvolvida pelos Grupos do CICECO.

Durante um ano, 20 líderes científicos mundiais discutirão as últimas novidades das suas respetivas áreas, abrindo novos caminhos para o futuro da ciência e da tecnologia de materiais, cruzando todos os aspetos da sociedade. Os seminários podem ser assistidos gratuitamente.

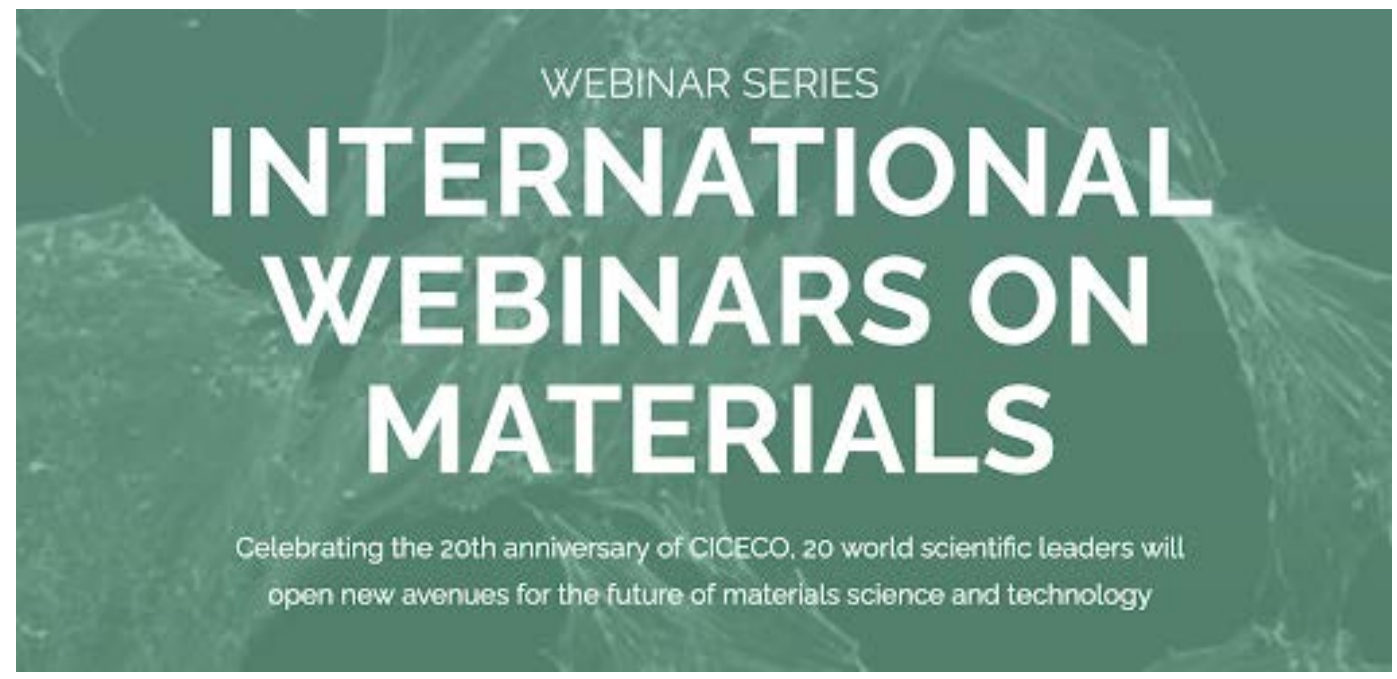

Mais informações em:

ciceco.ua.pt/iwmat

\section{Webinars Organizados pelo LAQV}

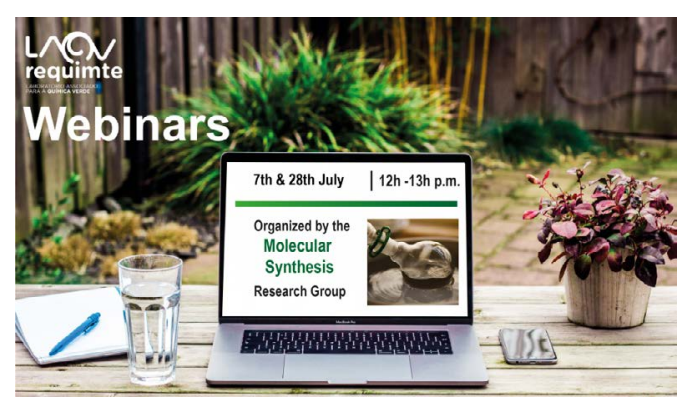

Mais informações em: laqv.requimte.pt/gazette
O Laboratório Associado para a Química Verde (LAQV) está a promover uma série de webinars mensais dedicados às atividades realizadas dentro de cada um dos seus grupos de investigação. 0 objetivo destes webinars é promover a discussão científica e a interação entre diferentes investigadores.

Cada grupo do LAQV é responsável pela organização de duas sessões por mês no âmbito da sua área de investigação. A participação é gratuita e não é necessário efetuar o registo para participar. 